www.jmscr.igmpublication.org

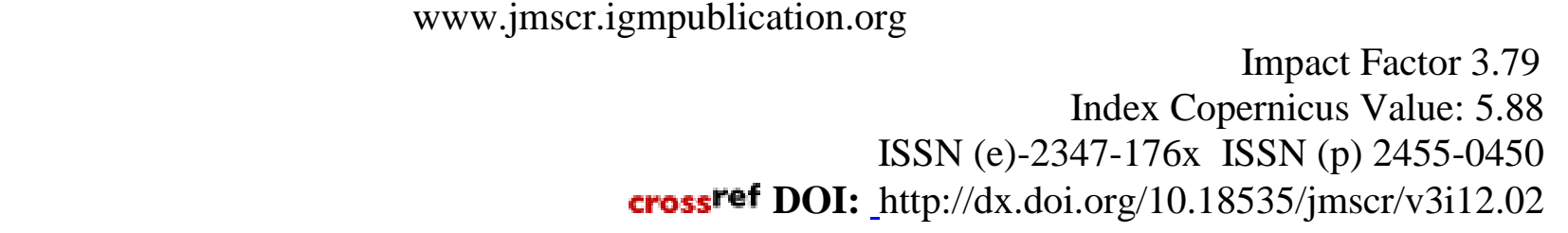

Journal Of Medical Science And Clinical Research

\title{
Misdistributions of Iron-Folic Acid (IFA): a Major deterrent to combat Anemia in Pregnant Women (ORIGINAL ARTICLE)
}

\begin{abstract}
Authors
\section{Dr M.K. Sharma ${ }^{1}$, Dr Neeraj Gour ${ }^{2}$, Dr N.K. Goel ${ }^{3}$, Dr Dinesh Walia ${ }^{4}$, Dr Navpreet ${ }^{5}$}

${ }^{1}$ Associate Professor, Deptt. of Community Medicine, Govt Medical College and Hospital, Chandigarh India

${ }^{2}$ Associate Professor, Deptt. of Community Medicine, SHKM Govt. Medical College, Mewat, Haryana India

${ }^{3}$ Professor \& Head, Deptt. of Community Medicine, Govt Medical College and Hospital, Chandigarh, India

${ }^{4}$ Assistant Professor, Deptt. of Community Medicine, Govt Medical College and Hospital, Chandigarh India

${ }^{5}$ Assistant Professor, Deptt.of Community Medicine, Govt Medical College and Hospital, Chandigarh, India

Dr Neeraj Gour
\end{abstract}

Flat No 602, B-2 Block, SHKM GMC Campus, Nalhar, Mewat (Haryana) India 122107

Email: drneeraj_g04@yahoo.com, Mobile:07837585818,08199997935

\section{ABSTRACT \\ INTRODUCTION: -}

As per WHO 2012 guidelines a pregnant women should receive IFA as soon as possible during gestation enabling pregnant women to consume a total of 180 tablets (though many countries aim for 90 tablets). Since, Antenatal care is an effective platform for IFA distribution and hence this study was conducted in this area covering the pregnant women

\section{AIMS and OBJECTIVES:-}

1. To divide pregnant women into categories based on their haemoglobin status.

2. To find out the final distribution of IFA to pregnant women who got registered within last 2 years.

\section{MATERIALS AND METHODS:}

The study was conducted at RHTC under the Department of Community Medicine of Govt. Medical College, Chandigarh

\section{RESULTS: -}

At Rural Health Training Center within a period of 02 years a total of 1651 pregnant women made use of antenatal services which included use of IFA tablets from second trimester onwards. Out of this 302(29.7\%) were not given any iron tablets and for those 744(70.3\%) who received IFA, it's distribution varied widely from 30 tablets in case of $25.5 \%$ to 90 tablets in case of $19.9 \%$ women.

\section{CONCLUSION AND RECOMMENDATION:-}

Inadequate, excess or unwanted distribution, happening even in Chandigarh raises the high presumption of its happening in other areas too. Our efforts must be channelised more in ensuring of getting IFA issued versus getting these consumed by the pregnant women.

KEY WORDS: misdistribution; IFA; pregnant women; anemia. 


\section{INTRODUCTION}

An entity which affects almost all sections of society to a significantly great extent is Anaemia of which many types occur. By far the commonest one is the Nutritional Anaemia. It can occur due to many reasons culminating in to non-interaction of factors required for haemoglobin synthesis including non-availability of iron. Considering the seriousness of the problem most National Governments have evolved control programmes to combat this menace. The Indian government did so in the year 1983-1984. However not much dent has been made in this direction and anaemia remains rampant. The saying of, "Things done by halves are never done right" holds true for anaemia as has been abruptly described by the Delhi based study ${ }^{1}$ which states that if pregnant women consumes less than recommended IFA tablets(less than 49) the fall in haemoglobin level was more $(0.82 \mathrm{gm} \%)$ compared to the fall $(0.27 \%)$ when no iron was consumed which emphasizes the need for complete treatment. The risk of neonatal deaths was decreased by $51 \%$ in Nepal and by $23 \%$ in Pakistan with any use of IFA compared to no use of IFA ${ }^{2}$.Many workers have given different clinico-adminstrative factors as most predominant in causation of anaemia starting from poor supply of IFA from store to health centres, to poor/non-consumption of the same by the consumers depending on its source, frequency (weekly, fortnightly, monthly), number of tablets issued in one time and regularity of distribution whether by Anganwadi Workers, Multipurpose Health Worker, Health Supervisor, Medical Officer or by other person delivering at Anganwadicentre, home of consumer, sub-centre, primary health centre or other place respectively ${ }^{3}$. The consumption of IFA critically depends on consumer's compliance which in turn depends on age, birth order and dose-frequency. Forgetfulness is an important reason (in $48.8 \%$ cases) of skipping IFA ${ }^{4}$. However, since the inception of National Programme takes place after many deliberations, the fault usually lies in its implementation which in the present circumstances means less IFAs made available to consumers. As per WHO 2012 guidelines a pregnant women should receive IFA as soon as possible during gestation enabling pregnant women to consume a total of 180 tablets (though many countries aim for 90 tablets). Since, Antenatal care is an effective platform for IFA distribution and hence this study was conducted in this area covering the pregnant women (the most representative group for study at facility level) as no such study has been conducted previously.

\section{AIMS AND OBJECTIVES}

1. To confirmissuance of IFA to the patient.

2. To assess percentage of pregnant women not receiving iron.

3. To divide pregnant women into categories based on their hemoglobin status.

4. To find out the final distribution of IFA to pregnant women who got registered within last 2 years.

5. To improve health services aiming to control anaemia in pregnant women.

\section{MATERIALS AND METHODS:}

In Chandigarh for only one district of population just about eleven lakhs, there are three Governments and hence its socio-economic status is very good. It has very good wider roads enabling the people to have quick access to health facilities. The study was conducted at RHTC under the Department of Community Medicine of Govt. Medical College, Chandigarh where female health workers from Department of Health of Chandigarh Administration are also posted. The maternal and Child Health Care (MCH) services are thus carried out by the mutual collaboration of Department of Medical Education and Department of Health along with its inherent benefits and drawbacks. The registers pertaining to antenatal care, however, are very well maintained since there completeness and thoroughness is frequently 
supervised by Female Health Supervisors and faculty members. The involvement of medical students in getting the antenatal mothers registered and investigated also added in strengthening the data management. The pilot analysis demonstrated that number of pregnant women having haemoglobin equal to or less than 7 gm per cent were only nil. Hence, the antenatal women with haemoglobin equal to or less than 8 gm per cent were put in the category of severe anemia. The same cut off point $<8 \mathrm{gm} / \mathrm{dl}$ to define severe anaemia has been used by other workers too 4. Haemoglobin was measured by cynmethhaemoglobin method. The woman with hemoglobin less than $11 \mathrm{gm}$ per cent was put in anaemic category and if her haemoglobin was 11 gm per cent or more, women were considered as non anaemic and were divided into 04 groups (up to 30 tablets, 31-60 tablets, 61 to 90 tablets and more than 90 tablets)by number of iron tablets consumed. Due to the reason of iron causing gastro-intestinal upset and which otherwise is very commonly experienced by first trimester pregnant women in the form of nausea, vomiting, hyperemesis, this group was excluded for finding out the amount of iron consumption/issuance to/by pregnant women. The data collected was pertaining only to previous two years (2012-13 and 2013-14) to avoid chances of duplicity. Out of all segments/subgroups of population, the subgroup of pregnant women remains best representative as majority of them report to health facilities. Hence study in this group. The data was analyzed in the form of tables. Percentages were calculated. Chi-square test was used to find out significance in differences.

\section{RESULTS}

At Rural Health Training Center within a period of 02 years a total of 1651 pregnant women made use of antenatal services which included use of IFA tablets from second trimester onwards. Out of these, 505 women were during first trimester of pregnancy. Thus, final analysis was limited to 1046 pregnant women. Out of this 302(29.7\%) were not given any iron tablets and for those744 (70.3\%) who received IFA, it's distribution varied widely from 30 tablets in case of $25.5 \%$ to 90 tablets in case of $19.9 \%$ women. For $283(27.5 \%)$ pregnant women haemoglobin estimation was not performed even once. From the table it is seen that contrary to expectations, more numbers, 145 (\%) of anemic mothers as against 37 (20.3\%) of non anemic mothers were not given IFA tablets. This proportion of not receiving IFA tablets was $18.9 \%$ for severely anaemic mothers. Amongst 571 anaemic mothers, 145 (25.4\%) were not issued IFA tablets and for remaining 426 women, only $144(25.2 \%)$ women were issued IFA tablets amounting to 90 or more (an ideal number for developing countries). As many as 102 (17.7\%) of such women were issued only 30 tablets. For 120 pregnant women neither hemoglobin estimation was done nor IFA tablets were issued.Observed effect of relation being non-significant may be because of the fact that many of the women might have not consumed iron or for that matter might have not been actually issued though it is recorded as being issued. Also in the diet consumed under Indian circumstances especially the one used by the women of low socioeconomic status might contain factors which interfere with iron absorption. 
Table no.1A - anaemia by no. of IFA tablets consumed

\begin{tabular}{|l|l|l|l|l|l|l|l|}
\hline Hb $(\mathbf{g m} \%)$ & $\mathbf{3 0}$ & $\mathbf{6 0}$ & $\mathbf{9 0}$ & $\mathbf{9 0 +}$ & $\begin{array}{l}\text { Sub } \\
\text { Total }\end{array}$ & NG & Grand Total \\
\hline $7-8$ & $15(9.1)$ & $11(8.3)$ & $8(8.0)$ & $13(7.0)$ & 47 & $34(18.9)$ & $81(10.6)$ \\
\hline $8.1-10.99$ & $87(53.0)$ & $92(69.6)$ & $6969.7)$ & $131(70.0)$ & 379 & $111(61.0)$ & $490(64.1)$ \\
\hline$=\&>11$ & $62(37.8)$ & $29(22.0)$ & $22(22.2)$ & $43(23.0)$ & 156 & $37(20.3)$ & $193(25.3)$ \\
\hline Sub- Total & $164(100)$ & $132(100)$ & $99(100)$ & $187(100)$ & 582 & $182(100)$ & $764(100)$ \\
\hline ND & $\begin{array}{l}103(36.4) \\
(38.6)\end{array}$ & $\begin{array}{l}29(10.2) \\
(18.0)\end{array}$ & $\begin{array}{l}10(3.5) \\
(9.2)\end{array}$ & $\begin{array}{l}21(7.4) \\
(10.1)\end{array}$ & 163 & $\begin{array}{l}120(42.4) \\
(39.4)\end{array}$ & $\begin{array}{l}283(100) \\
(27.5)\end{array}$ \\
\hline Over All & $\begin{array}{l}267(25.5) \\
(100)\end{array}$ & $\begin{array}{l}161(15.4) \\
(100)\end{array}$ & $\begin{array}{l}109(10.4) \\
(100)\end{array}$ & $\begin{array}{l}208(19.9) \\
(100)\end{array}$ & 744 & $\begin{array}{l}302(28.9) \\
(100)\end{array}$ & $\begin{array}{l}1046(100) \\
(100)\end{array}$ \\
\hline
\end{tabular}

ND- Hb not done, NG- IFA tablets not given

Table: 1B Two by two contingency table for IFA consumption

\begin{tabular}{|c|c|c|c|c|c|c|c|}
\hline Status & 30 & 60 & 90 & $90+$ & Sub Total & NG & Grand Total \\
\hline Anaemic & $\begin{array}{r}102(62.2) \\
(17.7)\end{array}$ & $\begin{array}{r}103(78.0) \\
(18.0)\end{array}$ & $\begin{array}{r}77(71.8) \\
(13.5)\end{array}$ & $\begin{array}{r}144(77.0) \\
(25.2)\end{array}$ & 426 & $\begin{array}{r}145(79.7) \\
(25.4)\end{array}$ & $\begin{array}{r}571(74.7) \\
(100.0)\end{array}$ \\
\hline $\begin{array}{l}\text { Non } \\
\text { Anaemic }\end{array}$ & $\begin{array}{r}62(37.8) \\
(32.1)\end{array}$ & $\begin{array}{r}29(22.0) \\
(15.0)\end{array}$ & $\begin{array}{r}22(22.2) \\
(11.4)\end{array}$ & $\begin{array}{r}43(23.0) \\
(22.3)\end{array}$ & 156 & $\begin{array}{r}37(20.3) \\
(19.2)\end{array}$ & $\begin{array}{c}193(25.3) \\
(100.0)\end{array}$ \\
\hline Sub- Total & $\begin{array}{r}164(100) \\
(21.5)\end{array}$ & $\begin{array}{r}132(100) \\
(17.3)\end{array}$ & $\begin{array}{r}99(100) \\
(13.0)\end{array}$ & $\begin{array}{r}187(100) \\
(24.1)\end{array}$ & 582 & $\begin{array}{r}182(100) \\
(23.8)\end{array}$ & $\begin{array}{r}764(100) \\
(100.0)\end{array}$ \\
\hline ND & $\begin{array}{r}103(36.4) \\
(38.6)\end{array}$ & $\begin{array}{r}29(10.2) \\
(18.0)\end{array}$ & $\begin{array}{r}10(3.5) \\
(9.2)\end{array}$ & $\begin{aligned} 21 & (7.4) \\
& (10.1)\end{aligned}$ & 163 & $\begin{array}{r}120(42.4) \\
(39.4)\end{array}$ & $\begin{array}{r}283(100) \\
(27.5)\end{array}$ \\
\hline Over All & $\begin{array}{c}267(25.5) \\
(100)\end{array}$ & $\begin{array}{c}161(15.4) \\
(100)\end{array}$ & $\begin{array}{c}109(10.4) \\
(100)\end{array}$ & $\begin{array}{r}208(19.9) \\
(100)\end{array}$ & 744 & $\begin{array}{c}302(28.9) \\
(100)\end{array}$ & $\begin{array}{r}1046(100) \\
(100)\end{array}$ \\
\hline
\end{tabular}

Table no.1C- table showing association of anemia with number of IFA tablets consumption.

\begin{tabular}{|l|l|l|l|}
\hline Anaemia & $\leq 90$ tablets & $>90$ tablets & Total \\
\hline Present & 282 & 144 & 426 \\
\hline Absent & 113 & 43 & 156 \\
\hline Total & 395 & 187 & 582 \\
\hline
\end{tabular}

Chi square- 4.764; DOF- 1; p- 0.2906

\section{DISCUSSION}

This study conducted in health care centre of city known by the name of city beautiful of India highlights the fact that things might not be as up to the mark as these look like or are propagated. In fact, not issuing IFA tablets to one-fourth of pregnant women is of serious concern. Similar is the case with basic investigation of haemoglobin estimation as in more than half of pregnant women it was not carried out. The document
"Standards for Maternal and Neonatal Care" developed by the Department of Making Pregnancy Safer, WHO states that the anaemia in pregnant women should be treated by daily iron doses of $120 \mathrm{~m} / \mathrm{g}$ for 03 months. Follow up should be done in 02 weeks to check clinical progress, test results and compliance and again 4 weeks later. Though the antenatal care is an effective platform for IFA distribution yet it was observed by a study ${ }^{5}$ conducted in populations of 
23 countries that an overall IFA coverage was $70 \%$ though it was little higher (79\%) among those women who attended antenatal care services. This figure of IFA coverage was $69.5 \%$, $44.3 \%$ and $75 \%$ among pregnant women of Nepal, Pakistan and Uganda respectively 5,6 similar figure in our study was $74.6 \%$. The frequency of its distribution was weekly, fortnightly, monthly, at one time and irregularly in case of $1.1 \%, 2.2 \%$, $34.6 \%, 21.9 \%$ and $3.1 \%$ respectively. Each time the number of tablets issued were 10, 20, 30-60, $60-90$ and $>90$ in case of $1.1 \%, 1.8 \%, 40.0 \%$, $16.6 \%$ and $3.0 \%$ respectively signifying the major distribution on bulk basis thus ignoring the value of follow up which is of paramount importance. In total $2.5 \%, 17.9 \%, 13.0 \%$ and $29.8 \%$ pregnant women received 10-29, 30-59, 60-89 and >90 tablets of IFA respectively ${ }^{3}$. In our study this frequency was fortnightly and monthly on 50\% basis. The total number of tablets issued to a pregnant female varied from 30 to 100 in most of the cases of different studies 1,3,5 including ours. An ideal of more than 90 tablets was received by only $30 \%$ of pregnant women in India7 and $10 \%$ in Bihar. The similar figure in our study was $25.4 \%$. An ideal of WHO recommended 180 tablets was received by only $9 \%$ of pregnant women in 23 countries ${ }^{5}$. As per Nepal UNICEF, Nepali Technical Assistance Group 2006, the IFA coverage was $73 \%$ in second trimester and $84 \%$ in $3^{\text {rd }}$ trimester.

\section{CONCLUSIONS AND RECOMMENDATIONS}

Inadequate, excess or unwanted distribution, happening even in Chandigarh raises the high presumption of its happening in other areas too. Our efforts must be channelised more in ensuring of getting IFA issued versus getting these consumed by the pregnant women. Promoting IFA intake by pregnant women requires addressing: logistic supplies and distribution of the facility, Health workers attitudes, counseling to better motivate women to attend atleast the recommended four ANC visits to complete the recommended IFA dosage.

\section{Source of funding: None \\ Conflict of interest: None}

\section{REFERENCES}

1. Varinder $\mathrm{T}$ Gautam, Yogesh Bansal, Devinder K Taneja, Gopal K Ingle. The study of compliance to IFA therapy and its effects on anaemia during pregnancy. Ind J. Prev.Soc,Med 2005, 36(4); 102-107.

2. Nisar Y B, Dibley M J (2014). Earlier initiation and use of a greater number of IFA supplementation during pregnancy prevent early neonatal death in Nepal and Pakistan. PLoS ONE, 9(11); e112446, doi; 10.1371/Journal. Phone.00112466, Nepal\&Pakistan Demographers and Health Survey (NDHS \& PDHS).

3. As per National Nutrition Monitoring Bureau (NNMB) 2002, a full data for Karnataka, Tamil Nadu, Kerala, Andhra Pradesh, Maharashtra, Madhya Pradesh, Orissa and West Bengal demonstrated that $62.7 \%$ of pregnant women received IFA.

4. P Mithra, B Unnikrishnan, T Rekha, K Nithin, K Mohan, V Kulkarani, and D Agarwal. Afr Health Sci, Dec 2013. Compliance with iron folic acid (IFA) therapy among pregnant women in an unban area of South India. www.ncbi.nlm.nih.gov/pmc/articles/PMC 5056486,

5. 5. D' Agostino A, Fiedler J, Nekatebeb H. A Rapid, Initial Assessment of the Distribution \& Consumption of IFA Tablets through Antenatal Care in 23 countries. 